\title{
Two New C-Glucosyl Benzoic Acids and Flavonoids from Mallotus nanus and Their Antioxidant Activity
}

\author{
Phan Van Kiem ${ }^{1}$, Nguyen Thi Mai ${ }^{1}$, Chau Van Minh ${ }^{1}$, Nguyen Huu Khoi ${ }^{1}$, Nguyen Hai Dang ${ }^{1}$, Nguyen Phuong \\ Thao', Nguyen Xuan Cuong ${ }^{1}$, Nguyen Hoai Nam ${ }^{1}$, Nguyen Xuan Nhiem ${ }^{1,2}$, Yvan Vander Heyden ${ }^{3}$, Joëlle Quetin- \\ Leclercq ${ }^{4}$, Gyo Nam Kim ${ }^{5}$, Hae Dong Jang ${ }^{5}$, and Young Ho Kim² \\ ${ }^{1}$ Institute of Natural Products Chemistry, Vietnam Academy of Science and Technology, 18 Hoang Quoc Viet, Caugiay, \\ Hanoi, Vietnam, ${ }^{2}$ College of Pharmacy, Chungnam National University, Daejeon 305-764, Korea, ${ }^{3} F A B I$, Vrije Univer- \\ siteit Brussel, Laarbeeklaan, 103 B-1090 Brussels, Belgium, ${ }^{4}$ Analytical chemistry, Drug Analysis and Pharmacognosy Unit, \\ Université Catholique de Louvain, Avenue E. Mounier, 72 B-1200 Brussels, Belgium, and ${ }^{5}$ Department of Food and \\ Nutrition, Hannam University, Daejeon 305-811, Korea
}

(Received May 22, 2009/Revised October 16, 2009/Accepted November 17, 2009)

Two new 2-C- $\beta$-D-glucopyranosyl benzoic acid derivatives named mallonanosides $\mathrm{A}(\mathbf{1})$ and $\mathrm{B}$ (2) were isolated from the methanolic extract of the leaves of Mallotus nanus along with five known flavonoids, kaempferin (3), juglanin (4), quercitrin (5), myricitrin (6), and rhoifolin (7). Their structures were established on the basis of spectral and chemical evidence. Their antioxidant activities were shown to depend on the number of hydroxyl groups, and the location and species of sugar moiety.

Key words: Mallotus nanus, C-glucosyl benzoic acid, Mallonanoside A, Mallonanoside B, Oxygen radical absorbance capacity

\section{INTRODUCTION}

Mallotus nanus Airy Shaw (Ba bet lun) belongs to Euphorbiaceae family, which is widely distributed from South Asia to South-East Asia. In Vietnam, this plant is found only in Kontum and Gialai provinces (Ho, 2003; Hoi et al., 2005). No studies on the chemical and bioactivities of this plant have yet been done. In the course of a phytochemical and biological study on Mallotus genus, we report herein the isolation, structural elucidation, and antioxidant activity of two new benzoic acid derivatives, mallonanosides A (1) and B (2), and five known flavonoids from the methanolic extract of the leaves of $M$. nanus.

The antioxidant activity of two benzoic acids and five flavonoids were measured using the oxygen radical absorbance capacity (ORAC) which is an acknowledged method for antioxidant assessment. The ORAC assay

Correspondence to: Young Ho Kim, College of Pharmacy, Chungnam National University, Daejeon 305-764, Korea

Tel: 82-42-821-5933, Fax: 82-42-823-6566

E-mail: yhk@cnu.ac.kr involves the completion of free radicals activities as a mean of quantitation, and combines both the extent of inhibition and the length of inhibition time of free radical action by antioxidants into a single quantity. The ORAC assay provides important information regarding the antioxidant capacity of various biological samples from pure compounds such as phenolic acids and flavonoids to complex matrices such as tea, fruits, vegetables, and animal tissues (Prior and Cao, 1999).

\section{MATERIALS AND METHODS}

\section{General methods}

Optical rotations were determined on a JASCO DIP1000 KUY polarimeter. All NMR spectra $\left({ }^{1} \mathrm{H},{ }^{13} \mathrm{C}\right.$, DEPT, HSQC, HMBC, COSY and ROESY) were recorded on a Bruker AM500 FT-NMR spectrometer (500 MHz for ${ }^{1} \mathrm{H}$ and $125 \mathrm{MHz}$ for ${ }^{13} \mathrm{C}$ ), and chemical shifts $(\delta)$ are reported in ppm using tetramethylsilane (TMS) as an internal standard. The ESI-MS was obtained on an AGILENT 1200 SERIES LC-MSD Trap spectrometer. HR-ESI-MS was recorded on a JEOL JMS-DX 303 mass spectrometer. Column chro- 
matography (CC) was performed on silica gel 230-400 mesh (0.040-0.063 mm, Merck) or YMC RP-18 resins (30-50 $\mu \mathrm{m}$, Fuji Silysia Chemical Ltd.). Thin layer chromatography (TLC) was performed on DC-Alufolien $60 \mathrm{~F}_{254}$ (Merck 1.05715) or $\mathrm{RP}_{18} \mathrm{~F}_{254 \mathrm{~s}}$ (Merck) plates. Spots were visualized by spraying $10 \% \mathrm{H}_{2} \mathrm{SO}_{4}$ aqueous and heating for $5 \mathrm{~min}$.

\section{Plant materials}

The leaves of $M$. nanus were collected in Kontum, Vietnam in May 2006 and identified by Prof. Nguyen Nghia Thin, College of Natural Sciences, Hanoi National University. An authentic sample ( $\left.\mathrm{N}^{\circ} \mathrm{MA23}\right)$ was deposited at the Herbarium of Institute of Natural Products Chemistry, VAST, Vietnam.

\section{Extraction and isolation}

The leaves of $M$. nanus ( $1.8 \mathrm{~kg}$ ) were powdered and extracted with methanol $(\mathrm{MeOH}, 3 \mathrm{~L})$ three times using a Sonicator (Ultrasonic 2010, 950W) at temperature of $50^{\circ} \mathrm{C}$ in $60 \mathrm{~min}$. The extract was concentrated under low pressure to obtain a $\mathrm{MeOH}$ extract (150.0 $\mathrm{g}$ ), which was suspended in water and successively partitioned with $n$-hexane and ethyl acetate (EtOAc) to obtain $n$-hexane $(35.0 \mathrm{~g})$ and EtOAc $(65.0 \mathrm{~g})$ extracts, successively. The aqueous layer was passed through a Dianion HP-20 column using a gradient concentration of $\mathrm{MeOH}$ in $\mathrm{H}_{2} \mathrm{O}(0: 100 ; 30: 70 ; 70: 30$; 100:0, v/v, $2 \mathrm{~L}$ ) as an eluent to give four fractions designated W0 (removed), W1 (15.0 g), W2 (19.0 g), and W3 $(11.0 \mathrm{~g})$. The EtOAc fraction $(65.0 \mathrm{~g})$ was chromatoghraphed on a silica gel column and eluted with $\mathrm{CHCl}_{3} / \mathrm{MeOH}$ gradient $(10: 1-1: 1, \mathrm{v} / \mathrm{v})$ to obtain three sub-fractions designated E3A (26.5 g), E3B (13.4 g), and E3C (24.0 g). The E3A sub-fraction (26.5 g) was chromatographed on an YMC RP-18 column and eluted with $\mathrm{MeOH} / \mathrm{H}_{2} \mathrm{O}(4: 1, \mathrm{v} / \mathrm{v})$ to yield $3(20.5 \mathrm{mg})$ and $4(9.0 \mathrm{mg})$ as yellow amorphous powders. The E3B sub-fraction (13.4 g) was chromatographed on an YMC RP-18 column and eluted with $\mathrm{MeOH} / \mathrm{H}_{2} \mathrm{O}(5: 2$ $\mathrm{v} / \mathrm{v})$ to give $5(15.0 \mathrm{mg})$ and $6(12.0 \mathrm{mg})$ as yellow amorphous powders. The E3C sub-fraction $(24.0 \mathrm{~g})$ was chromatographed on a silica gel column and eluted with $\mathrm{CHCl}_{3} / \mathrm{MeOH} / \mathrm{H}_{2} \mathrm{O}$ (3:1:0.1, v/v/v) yielding 1 (120.0 mg) as a white amorphous powder. The W1 fraction was chromatographed on a silica gel column and eluted with $\mathrm{CHCl}_{3} / \mathrm{MeOH} / \mathrm{H}_{2} \mathrm{O}(2: 1: 0.2, \mathrm{v} / \mathrm{v} / \mathrm{v})$ to obtain $7(35.0 \mathrm{mg})$ as a yellow amorphous powder. Compound 2 (100.0 mg) was recrystallized in $\mathrm{MeOH}$ from the W2 fraction.

\section{Mallonanoside A (1)}

White amorphous powder; $\mathrm{mp} 196-197^{\circ} \mathrm{C} ;[\alpha]_{\mathrm{D}}^{25}+55^{\circ}(c$ 0.50, $\left.\mathrm{CHCl}_{3}\right)$; IR (KBr) cm ${ }^{-1}: 3440(\mathrm{OH}), 2954(\mathrm{CH})$, $1725(\mathrm{C}=\mathrm{O}), 1620$ and $1580(\mathrm{C}=\mathrm{C})$; positive ESI-MS $\mathrm{m} /$ $z 347[\mathrm{M}+\mathrm{H}]^{+}$, negative ESI-MS $m / z 327\left[\mathrm{M}-\mathrm{H}_{2} \mathrm{O}-\mathrm{H}\right]^{-}$; HR-ESI-MS $m / z 351.0710\left[\mathrm{M}-\mathrm{H}_{2} \mathrm{O}+\mathrm{Na}\right]^{+}$(Calcd for $\mathrm{C}_{14} \mathrm{H}_{16} \mathrm{O}_{9} \mathrm{Na}$ 351.0692); ${ }^{1} \mathrm{H}$ NMR (500 MHz, $\mathrm{CD}_{3} \mathrm{OD}$ ) and ${ }^{13} \mathrm{C}$ NMR (125 MHz, $\left.\mathrm{CD}_{3} \mathrm{OD}\right)$ : See Table I.

\section{Mallonanoside B (2)}

White crystals; mp $201-202^{\circ} \mathrm{C} ;[\alpha]_{\mathrm{D}}^{25}+57^{\circ}$ (c 0.50 , $\left.\mathrm{CHCl}_{3}\right)$; IR (KBr) cm ${ }^{-1}: 3450(\mathrm{OH}), 2953(\mathrm{CH}), 1723$ $(\mathrm{C}=\mathrm{O}), 1625$ and $1580(\mathrm{C}=\mathrm{C})$; positive ESI-MS $\mathrm{m} / \mathrm{z}$ $315\left[\left(\mathrm{M}-\mathrm{H}_{2} \mathrm{O}\right)+\mathrm{H}\right]^{+}$, negative ESI-MS $m / z 313[\mathrm{M}$ $\left.\mathrm{H}_{2} \mathrm{O}-\mathrm{H}\right]^{-}$; HR-ESI-MS $m / z 337.0550 \quad\left[\mathrm{M}-\mathrm{H}_{2} \mathrm{O}+\mathrm{Na}\right]^{+}$ (Calcd for $\left.\mathrm{C}_{13} \mathrm{H}_{14} \mathrm{O}_{9} \mathrm{Na} 337.0536\right) ;{ }^{1} \mathrm{H}$ NMR $(500 \mathrm{MHz}$, DMSO- $\left.d_{6}\right)$ and ${ }^{13} \mathrm{C}$ NMR (125 MHz, DMSO- $\left.d_{6}\right)$ : See

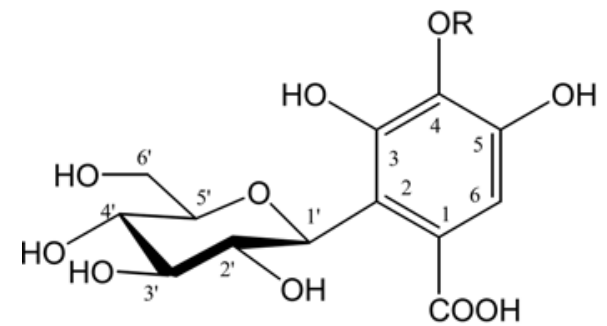

$1 \mathrm{R}=\mathrm{CH}_{3}$

$2 \mathrm{R}=\mathrm{H}$

Fig. 1. Structures of isolated compounds (1-7)

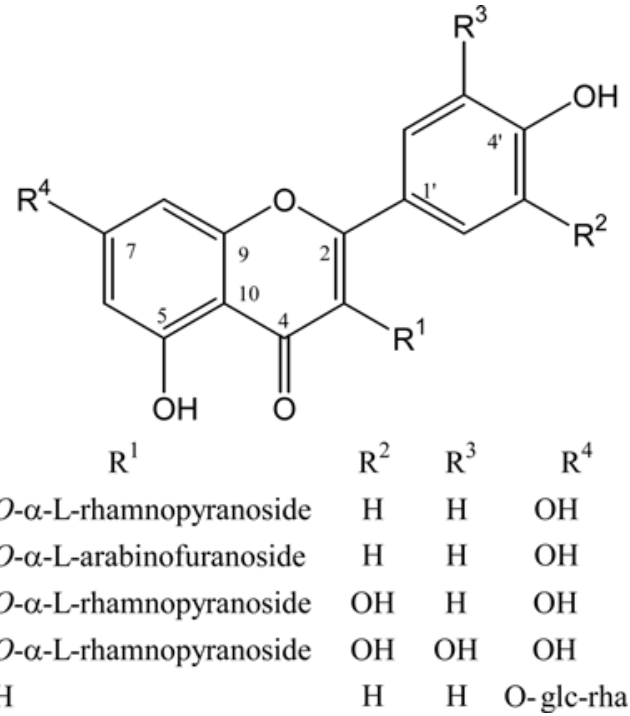


Table I. NMR data of $\mathbf{1}$ and $\mathbf{2}$

\begin{tabular}{|c|c|c|c|c|}
\hline \multirow{2}{*}{$\mathrm{C}$} & \multicolumn{2}{|r|}{1} & \multicolumn{2}{|r|}{2} \\
\hline & $\delta_{C}^{a, b}$ & $\delta_{\mathrm{H}}{ }^{\mathrm{a}, \mathrm{c}}$ mult. $(J, \mathrm{~Hz})$ & $\delta_{C}^{d, b}$ & $\delta_{\mathrm{H}}^{\mathrm{d}, \mathrm{c}}$ mult. $(J, \mathrm{~Hz})$ \\
\hline 1 & 119.4 & - & 116.2 & - \\
\hline 2 & 117.2 & - & 112.9 & - \\
\hline 3 & 149.5 & - & 142.6 & - \\
\hline 4 & 142.5 & - & 139.8 & - \\
\hline 5 & 152.7 & - & 146.1 & - \\
\hline 6 & 111.2 & $7.08 \mathrm{~s}$ & 109.5 & $6.96 \mathrm{~s}$ \\
\hline $\mathrm{OCH}_{3}$ & 60.9 & $3.90 \mathrm{~s}$ & - & - \\
\hline $\mathrm{COOH}$ & 165.8 & - & 163.9 & - \\
\hline & & $C$-glc & & \\
\hline $1^{\prime}$ & 74.3 & $4.94 \mathrm{~d}(10.5)$ & 72.4 & $4.93 \mathrm{~d}(10.5)$ \\
\hline $2^{\prime}$ & 81.5 & $4.05 \mathrm{dd}(9.5,10.5)$ & 79.9 & $3.91 \mathrm{dd}(9.5,10.5)$ \\
\hline $3^{\prime}$ & 75.1 & $3.80 \mathrm{dd}(9.0,9.5)$ & 73.9 & $3.63 \mathrm{dd}(9.0,9.5)$ \\
\hline $4^{\prime}$ & 72.0 & $3.42 \mathrm{dd}(9.0,9.5)$ & 71.0 & 3.18 t $(9.0)$ \\
\hline $5^{\prime}$ & 83.1 & $3.66 \mathrm{~m}$ & 81.7 & $3.55 \mathrm{~m}$ \\
\hline $\mathbf{6}^{\prime}$ & 62.7 & $\begin{array}{l}3.68 \mathrm{dd}(5.5,12.0) \\
4.03 \mathrm{dd}(2.5,12.0)\end{array}$ & 61.4 & $\begin{array}{l}3.41 \text { dd }(5.5,12.0) \\
3.83 \text { dd }(2.5,12.0)\end{array}$ \\
\hline
\end{tabular}

${ }^{\mathrm{a}}$ Measured in $\mathrm{CD}_{3} \mathrm{OD},{ }^{\mathrm{b}} 125 \mathrm{MHz},{ }^{\mathrm{c}} 500 \mathrm{MHz},{ }^{\mathrm{d}}$ measured in DMSO- $d_{6}$, chemical shifts in ppm

Table I.

\section{Oxygen radical absorbance capacity (ORAC) assay}

The assay was carried out on a Tecan GENios multifunctional plate reader (Tecan) with fluorescent filters using excitation and emission wavelengths of $485 \mathrm{~nm}$ and $535 \mathrm{~nm}$, respectively. In the final assay mixture, $40 \mathrm{nM}$ fluorescein was used as a target of free radical attack with either $20 \mathrm{mM} \mathrm{2,2-azobis} \mathrm{dihydrochloride}$ (AAPH) as a peroxyl radical generator in a peroxyl radical-scavenging capacity $\left(\mathrm{ORAC}_{\mathrm{ROO}}\right.$.) assay (Kurihara et al., 2004) or $\mathrm{H}_{2} \mathrm{O}_{2}-\mathrm{CuSO}_{4}\left(\mathrm{H}_{2} \mathrm{O}_{2}, 0.75 \% ; \mathrm{CuSO}_{4}, 5\right.$ $\mu \mathrm{M})$ as mainly a hydroxyl radical generator in a hydroxyl radical-scavenging capacity $\left(\mathrm{ORAC}_{\mathrm{OH}}\right.$.) assay (Cao et al., 1997). Trolox (1 $\mu \mathrm{M})$ was used as a control standard and prepared fresh daily. The analyzer was programmed to record the fluorescence of fluorescein every 2 min after addition of AAPH or $\mathrm{H}_{2} \mathrm{O}_{2}-\mathrm{CuSO}_{4}$. All fluorescence measurements were expressed relative to the initial reading. Final results were calculated based on the difference in the area under the fluorescence decay curve between the blank and each sample. $\mathrm{ORAC}_{\mathrm{ROO}}$. and $\mathrm{ORAC}_{\mathrm{OH}}$. were expressed as micromoles of Trolox equivalents (TE). One ORAC unit is equivalent to the net protection area provided by $1 \mu \mathrm{M}$ of Trolox.

\section{Determination of reduction capacity}

The reducing abilities of isolated compounds were determined according to the method of Aruoma et al. (1998). The forty micro-liters of different concentrations of the compounds in distilled water were mixed with $160 \mu \mathrm{L}$ of the mixture containing $0.5 \mathrm{mM} \mathrm{CuCl}_{2}$ and $0.75 \mathrm{mM}$ neocuproine in $10 \mathrm{mM}$ phosphate buffer, $\mathrm{pH}$ 7.4. The absorbance was measured with a micro-plate reader at $454 \mathrm{~nm}$ for $1 \mathrm{hr}$. Increased absorbance of the reaction mixture indicates increased reducing power.

\section{Metal chelating activity}

The metal chelating activities of isolated compounds were measured by the competitive binding procedure of Agirova and Ortherth (Agirova and Ortherth, 2003). One hundreds micro-liters of different concentration of the compounds were mixed with $100 \mu \mathrm{L}$ of $0.1 \mu \mathrm{M} \mathrm{CuSO}$. After one hundred micro-liters of mixture solution was added to $100 \mu \mathrm{L}$ of $0.1 \mu \mathrm{M}$ calcein, the fluorescence of mixture solution was measured using a Tecan GENios multi-functional plate reader with fluorescent filters (excitation wavelength: 485 $\mathrm{nm}$ and emission filter: $535 \mathrm{~nm}$ ) and compared to the fluorescence intensity of control which contained only calcein.

\section{Statistical analysis}

All data are presented as means \pm S.D. Statistical analyses were done using statistical package SPSS (Statistical Package for Social Science, SPSS Inc.) program, and significance of each group was verified with the analysis of One-way ANOVA followed by the Duncan's test of $p<0.05$.

\section{RESULTS AND DISCUSSION}

Compound 1 was obtained as an amorphous powder. The ESI mass spectrum of 1 showed the quasi molecular ion peak at $m / z 347[\mathrm{M}+\mathrm{H}]^{+}$(positive ion mode) and $m / z 327\left[\mathrm{M}-\mathrm{H}_{2} \mathrm{O}-\mathrm{H}\right]^{-}$(negative ion mode) corresponding to the molecular formula of $\mathrm{C}_{14} \mathrm{H}_{18} \mathrm{O}_{10}$, which was further confirmed by high resolution time of flight (TOF) ESI-MS (found $m / z 351.0710\left[\mathrm{M}-\mathrm{H}_{2} \mathrm{O}\right.$ $+\mathrm{Na}]^{+}$, calcd for $\mathrm{C}_{14} \mathrm{H}_{16} \mathrm{O}_{9} \mathrm{Na}$ 351.0692). The ${ }^{1} \mathrm{H}$ NMR spectrum displayed only a singlet signal at $\delta 7.08$, suggesting for the presence of a penta-substituted aromatic ring, and a methoxyl group at $\delta 3.90$ (s). The doublet signal at $\delta 4.94$ with large coupling constant $(J=10.5 \mathrm{~Hz})$ was indicative of a $C$-glucopyranosyl structure (EI-Sayed et al., 2006), which was further confirmed by the oxymethylene signals at $\delta 4.03(\mathrm{dd}, J$ $=2.5,12.0 \mathrm{~Hz}) / 3.68(\mathrm{dd}, J=5.5,12.0 \mathrm{~Hz})$ and the other oxymethine signals at the range of $\delta 3.42-\delta$ 4.94. The ${ }^{13} \mathrm{C} N M R$ spectrum of 1 displayed resonances due to the presence of one methoxyl group at $\delta 60.9$, 
one carboxyl carbon at $\delta 165.8$, and six aromatic carbon signals at $\delta 111.2,117.2,119.4,142.5,149.5$, and 152.7. The six remaining carbon signals were assigned to a $C$ - $\beta$-D-glucopyranosyl moiety by comparison with the published data (EI-Sayed et al., 2006). The longrange correlations between $\mathrm{H}-1^{\prime}\left(\delta_{\mathrm{H}} 4.94\right)$ and $\mathrm{C}-1\left(\delta_{\mathrm{C}}\right.$ $119.4) / \mathrm{C}-2\left(\delta_{\mathrm{C}} 117.2\right) / \mathrm{C}-3\left(\delta_{\mathrm{C}} 149.5\right)$, and between $\mathrm{H}-2$ ' $\left(\delta_{\mathrm{H}} 4.05\right)$ and $\mathrm{C}-1^{\prime}\left(\delta_{\mathrm{C}} 74.3\right) / \mathrm{C}-2\left(\delta_{\mathrm{C}} 117.2\right)$ were observed in the heteronuclear multiple bond correlation (HMBC) spectrum confirming that the $C$-glucosyl moiety was attached to $\mathrm{C}-2$ of the aglycone, the carboxylic group was linked to $\mathrm{C}-1$, and the hydroxyl was linked to C-3. HMBC cross peaks between methoxyl proton $(\delta 3.90)$ and C-4 ( $\delta$ 142.5), between H-6 $(\delta$ 7.08) and C-4/C-1/C$2 / \mathrm{COOH}$ confirmed the location of $\mathrm{C}-4$ methoxyl group and H-6. The detailed HMBC analysis shown in Fig. 2 confirmed the location and the chemical shift assignments of the aromatic ring substituted groups. Thus, 1 was characterized as 3,5-dihydroxy-4-methoxy-2-C$\beta$-D-glucopyranosylbenzoic acid, named mallonanoside A.

Compound $\mathbf{2}$ was recrystallized from the water fraction. ${ }^{1} \mathrm{H}$ NMR spectra of $\mathbf{2}$ were very similar to those of 1, except for the disappearance of the methoxyl signal suggesting that $\mathbf{2}$ was a demethoxyl derivative of 1 . Thirteen carbon signals were observed in the ${ }^{13} \mathrm{C}$ NMR spectrum of $\mathbf{2}$ including six aromatic, one carboxyl, and six signals attributed to a $C$-glucopyranosyl residue. The structure of $\mathbf{2}$ was further confirmed by extensive HSQC and HMBC studies (Fig. 2). Moreover, the ESI-MS of 2 showed the quasi molecular ion peaks at $m / z 315\left[\mathrm{M}-\mathrm{H}_{2} \mathrm{O}+\mathrm{H}\right]^{+}$(positive ion mode) and $m /$ $z 313\left[\mathrm{M}-\mathrm{H}_{2} \mathrm{O}-\mathrm{H}\right]^{-}$(negative ion mode) corresponding to the molecular formula of $\mathrm{C}_{13} \mathrm{H}_{16} \mathrm{O}_{10}$, which was further confirmed by high resolution TOF ESI-MS (found $m / z 337.0550\left[\mathrm{M}-\mathrm{H}_{2} \mathrm{O}+\mathrm{Na}^{+}\right.$, calcd for $\mathrm{C}_{13} \mathrm{H}_{14} \mathrm{O}_{9} \mathrm{Na}$ 337.0536). From the current evidence and comparison with published data (EI-Sayed et al., 2006), the structure of $\mathbf{2}$ was proposed to be 3,4,5trihydroxy-2- $C$ - $\beta$-D-glucopyranosylbenzoic acid, which was named mallonanoside $\mathrm{B}$.

Compounds 3-7 were identified as kaempferin
(Kaouadji, 1990), juglanin (Kim et al., 1994), quercitrin (Xi-Ning et al., 1997), myricitrin (Xi-Ning et al., 1997), and rhoifolin (Kaneko et al., 1995), respectively.

The antioxidant capacity of seven compounds isolated from the leaves of $M$. nanus was measured by ORAC, which has been recently accepted as a standard method to analyze the antioxidant potential of active substances of plants (Cao et al., 1997; Kurihara et al., 2004). Mallonanoside A (1) showed higher peroxyl radical-scavenging activity than mallonanoside B (2) (Fig. 3). The methoxyl group substituted for hydroxyl group at the C-4 of mallonanoside A (1) can contribute to peroxyl radical-scavenging activity since it displayed stronger reduction potential than mallonanoside B (2) (Fig. 5). The antioxidant peroxyl radical scavenging capacity of compounds 3-7 was significantly higher than those of the positive control, trolox. Also, the scavenging capacity was dependent on the

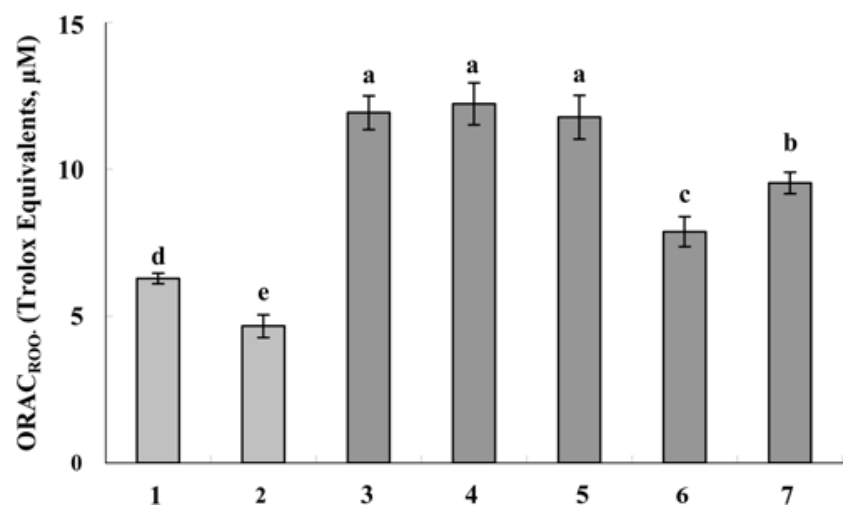

Fig. 3. Peroxyl radical-scavenging activity (Trolox equivalent, $\mu \mathrm{M}$ ) of compounds 1-7. The ORAC value is calculated by dividing the area under the sample curve by the area under the Trolox curve, with both areas being corrected by subtracting the area under the blank curve. One ORAC unit is assigned as the net area of protection provided by Trolox at a final concentration of $1 \mu \mathrm{M}$. The area under the curve of the sample is compared to the area under the curve for Trolox, and the antioxidative value is expressed in micromoles of Trolox equivalent per liter. The results represent the mean \pm S.D. of values obtained from three measurements. Different corresponding letters indicate significant differences at $p<0.05$ by Duncan's test.
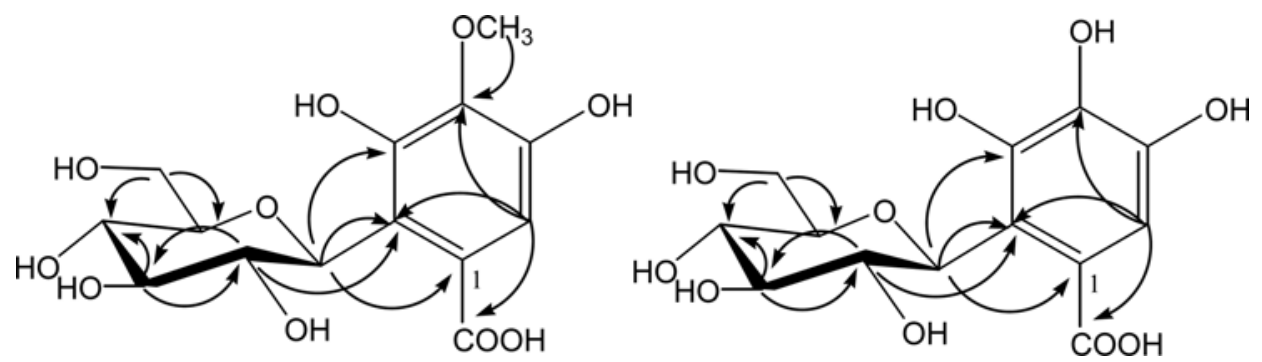

Fig. 2. HMBC correlations of $\mathbf{1}$ and 2 


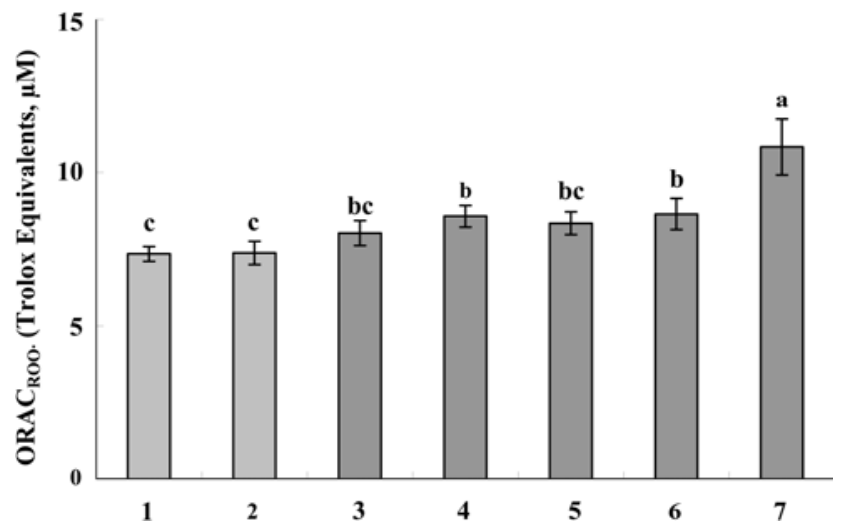

Fig. 4. Hydroxyl radical-scavenging activity (Trolox equivalent, $\mu \mathrm{M}$ ) of compounds 1-7. The ORAC value is calculated by dividing the area under the sample curve by the area under the Trolox curve, with both areas being corrected by subtracting the area under the blank curve. One ORAC unit is assigned as the net area of protection provided by Trolox at a final concentration of $1 \mu \mathrm{M}$. The area under the curve of the sample is compared to the area under the curve for Trolox, and the antioxidative value is expressed in micromoles of Trolox equivalent per liter. The results represent the mean \pm S.D. of values obtained from three measurements. Different corresponding letters indicate significant differences at $p<0.05$ by Duncan's test.

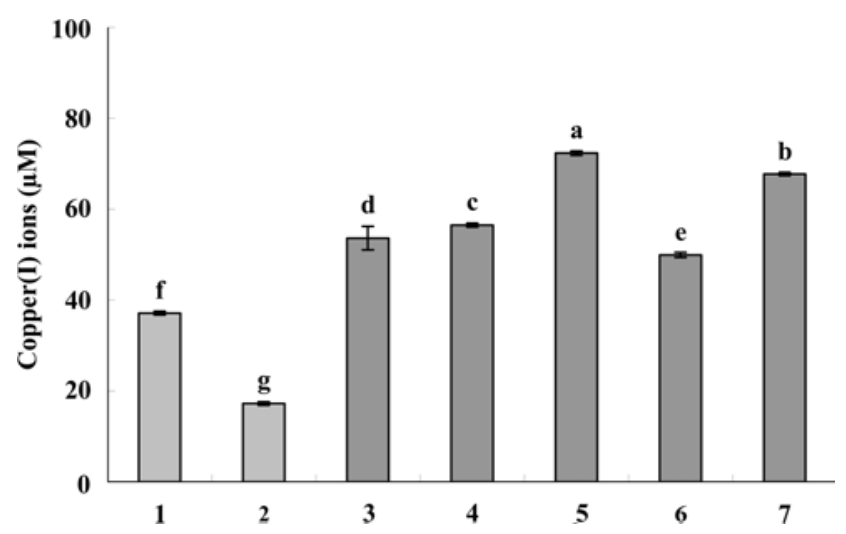

Fig. 5. Reduction potential of compounds 1-7. Different letters are significantly different $(p<0.05)$.

location and number of hydroxyl groups, and the location and species of sugar moiety in their structures (Fig. 3). The peroxyl radical-scavenging activities of compounds 3-7 could not be explained solely by their reduction potentials to donate hydrogens or electrons because the former did not exhibited the linear relation with the latter (Figs. 3 and 5). Mallonanoside A (1) showed the same level of hydroxyl radical-scavenging activity as mallonanoside B (2), but mallonanoside B (2) with a hydroxyl group demonstrated stronger metal chelating activity than mallonanoside A (1) with a methoxyl group. The hydroxyl radical-scavenging activities of compounds 3 -

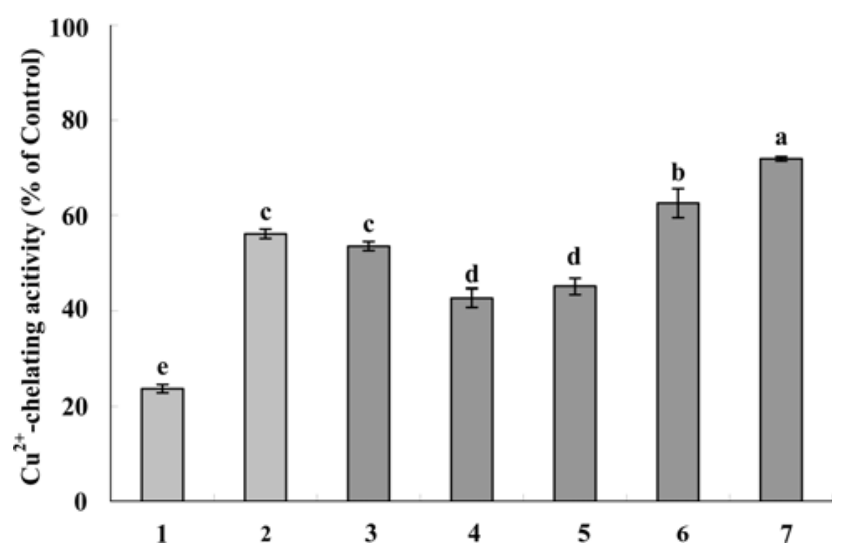

Fig. 6. Metal chelating activity of compounds 1-7. Different letters are significantly different $(p<0.05)$.

7 were almost same except for compound 7 with a disaccharide consisting of glucose and rhamnose at the C-7 position. However, compound 7 with a disaccharide at the C-7 position showed the strongest metal chelating activity among compounds 3-7, followed by the compound $\mathbf{6}$ with rhamnose at the position C-3 and three hydroxyl groups (Fig. 6). These results suggest that the hydroxyl radical-scavenging activities of compounds $\mathbf{3 - 7}$ as determined by the ORAC assay may be attributed to the combined effect of their scavenging activities against hydroxyl radical and metal chelating activities.

\section{ACKNOWLEDGEMENTS}

This work was supported by the bilateral cooperation project between Vietnam and Belgium, and Priority Research Centers Program through the National Research Foundation of Korea (NRF) funded by the Ministry of Education, Science and Technology (20090093815). The authors are grateful to Prof. Nguyen Nghia Thin, College of Natural Sciences, Hanoi National University for the plant collecting and identification. We thank Mr Dang Vu Luong, Institute of Chemistry, VAST and KBSI for the measuring NMR spectra.

\section{REFERENCES}

Argirova, A. D. and Ortwerth, B. J., Activation of proteinbound copper ions during early glycation: study on two proteins. Arch. Biochem. Biophys., 420, 176-184 (2003).

Aruoma, O. I., Deiana M., Jenner, A., Halliwell, B., Kaur, H., Banni, S., Corongiu, F. P., Dessi, M. A., and Aeschbach, R., Effect of hydroxytyrosol found in extra virgin olive oil on oxidative DNA damage and on low-density lipoprotein oxidation. J. Agric. Food Chem., 46, 5181-5187 (1998). 
Cao, G., Sofic, E., and Prior, R. L., Antioxidant and prooxidant behavior of flavonoids: structure activity relationships. Free Radic. Biol. Med., 22, 749-760 (1997).

El-Sayed, N. H., Ammar, N. M., Al-Okbi, S. Y., Abou ElKassem, L. T., and Mabry, T. J., Antioxidant activity and two new flavonoids from Washingtonia filifera. Nat. Prod. Res., 20, 57-61 (2006).

Ho, P. H., An Illustrated Flora of Vietnam. Tre Publishing House, Ho Chi Minh, pp. 250-251, (2003).

Hoi, T. M., Huyen, D. D., Thai, T. H., and Ban, N. K., Vietnamese plant resources-Bioactive compounds containing plants. Agriculture Publishing House, Hanoi, pp. 4757, (2005).

Kaneko, T., Sakamoto, M., Ohtani, K., Ito, A., Kasai, R., Yamasaki, K., and Padorina, W., Secoiridoid and flavonoid glycosides from Gonocaryum calleryanum. Phytochemistry, 39, 115-129 (1995).
Kaouadji, M., Acylated and non-acylated kaempferol monoglycosides from Plantanus acerifolia Buds. Phytochemistry., 29, 2295-2297 (1990).

Kim, H. J., Woo, E. R., and Park, H., A novel lignan and flavonoids from Polygonum aviculare. J. Nat. Prod., 57, 581-586 (1994).

Kurihara, H., Fukami, H., Asami, S., Totoda, Y., Nakai, M., Shibata, H., and Yao, X. S., Effects of oolong tea on plasma antioxidative capacity in mice loaded with restraint stress assessed using the oxygen radical absorbance capacity (ORAC) assay. Biol. Pharm. Bull., 27, 1093-1098 (2004)

Prior, R. L. and Cao, G., In vivo total antioxidant capacity: Comparison of different analytical method. Free Radic. Biol. Med., 27, 1173-1181 (1999).

Xi-Ning, Z., Hideaki, O., Ide, T., Hirata, E., Takushi, A., and Takeda, Y., Three flavonol glysosides from leaves of Myrsine segnuinii. Phytochemistry, 46, 943-946 (1997). 